\title{
Glucagon Shortens Cecal Intubation Time and Total Procedure Time During Colonoscopy: A Prospective, Double-Blind Placebo Controlled Randomized Trial
}

\author{
Anupam Aditi ${ }^{1 \#}$, Trilokesh Dey Kidambi"\#, Angel Espinoza ${ }^{3}$, Nicholas Crowley ${ }^{3}$, Alex Rodas*3 and John \\ Patrick Cello ${ }^{3,4}$ \\ ${ }^{1}$ Division of Gastroenterology, inSite Digestive Health Care, Daly City, California, USA \\ ${ }^{2}$ Division of Gastroenterology, City of Hope National Medical Center, Duarte, California, USA \\ ${ }^{3}$ Division of Gastroenterology, Zuckerberg San Francisco General Hospital, San Francisco, California, USA
}

${ }^{4}$ Division of Gastroenterology, University of California, San Francisco, California, USA

\#Anupam Aditi and Trilokesh Dey Kidambi contributed equally as co-first authors

*Corresponding author: Alex Rodas, San Francisco General Hospital, 1001 Potrero Avenue, Bldg. 5, Unit 3-D, San Francisco CA 94110, USA

\begin{tabular}{|c|c|}
\hline ARTICLE INFO & ABSTRACT \\
\hline $\begin{array}{l}\text { Received: 慧 October 05, } 2019 \\
\text { Published: } 1 \text { October 18, } 2019\end{array}$ & $\begin{array}{l}\text { Background: Impact of antispasmodics use, such as glucagon, during screening } \\
\text { colonoscopy is largely unknown. }\end{array}$ \\
\hline $\begin{array}{l}\text { tation: Anupam Aditi, Trilokesh Dey } \\
\text { idambi, Angel Espinoza, Nicholas Crow- } \\
\text { y, Alex Rodas, John Patrick Cello. Gluca- } \\
\text { on Shortens Cecal Intubation Time and }\end{array}$ & $\begin{array}{l}\text { Methods: A prospective, double-blind, placebo-controlled randomized trial to } \\
\text { evaluate the effect of glucagon during colonoscopy was performed. Parameters such as } \\
\text { cecalintubation time, total procedure time, adenoma detection rate [ADR], serrated polyp } \\
\text { detection rate [SDR], degree of spasm, adequacy of visualization, scope manipulation } \\
\text { and patient pain score were prospectively recorded. }\end{array}$ \\
\hline $\begin{array}{l}\text { Total Procedure Time During Colonosco- } \\
\text { y: A Prospective, Double-Blind Placebo } \\
\text { Controlled Randomized Trial. Biomed } \\
\text { Sci \& Tech Res 22(2)-2019. BJSTR. } \\
\text { MS.ID.003713. }\end{array}$ & $\begin{array}{l}\text { Results: Cecal intubation time and total procedure time was shortened with } \\
\text { glucagon use. A trend towards improved serrated polyp detection [SDR] and neoplasia } \\
\text { detection rate [NDR] was seen with glucagon use. Endoscopists noted improved scope } \\
\text { manipulation with glucagon use. }\end{array}$ \\
\hline $\begin{array}{l}\text { Keywords: Colonoscopy; Glucagon; Cecal } \\
\text { ntubation Time; Procedure Time }\end{array}$ & $\begin{array}{l}\text { Conclusion: Glucagon use during screening colonoscopy leads to shorter total } \\
\text { procedure time and improved endoscopist scope manipulation. Association between } \\
\text { glucagon use and increased NDR is noted but requires larger studies powered to evaluate } \\
\text { NDR as a primary outcome. }\end{array}$ \\
\hline
\end{tabular}

\section{Introduction}

Colonoscopy is the most commonly performed procedure by gastroenterologists in the United States and in most of the developed world. It is most commonly used for detection and removal of benign polyps, neoplastic polyps and colon cancer. The National Polyp Study demonstrated a significant decrease in the incidence of colorectal cancer following endoscopic removal of polyps detected during screening colonoscopy [1]. Currently, however, only $50 \%$ of Americans at risk for development of colorectal cancer are being screened with a colonoscopy [2]. Attempts to increase the rate of screening are limited by the total number of colonoscopies that can be performed daily in the United States [2]. Thus, identifying interventions that decrease the duration of colonoscopy without compromising quality metrics, such as polyp detection, can lead to an increase in the clinical impact of colonoscopy for colon cancer prevention. Colonoscopy can be complicated by colonic spasms, which leads to patient discomfort, longer procedure times, 
increased use of sedatives and operator fatigue [3]. Glucagon is an intravenously administered anti-spasmodic agent that relaxes gastrointestinal smooth muscle and produces a prompt effect following administration $[4,5]$.

Its short serum half-life (8-18 minutes) and minimal side effects at the standard dose of 1 milligram (mg) make it an attractive spasmolytic over otheranti-cholinergicdrugs [3]. While it is routinely used during endoscopic retrograde cholangiopancreatography (ERCP) to inhibit peristalsis to facilitate cannulation of the papilla, it is uncommonly used during colonoscopy. Glucagon has the theoretical benefit of facilitating colonoscope passage by decreasing peristalsis and improving visualization and detection of polyps through the flattening of haustral folds. To our knowledge, three previous studies have studied the effect of glucagon during routine colonoscopy [6-8]. Results from these studies are conflicting and ranged from increased procedural difficulty for the endoscopist and increased patient side effects to improved patient tolerance and faster cecal intubation time with the administration of glucagon [68]. Only one of these studies was performed with current standard high definition colonoscope and thus most reports do not account for technological improvements in the colonoscope and insertion techniques [8]. Furthermore, none of the prior studies reported on the effect of glucagon on adenoma detection rate (ADR).

Cecal intubation time, defined as the time required to reach the cecum after insertion, is an important measure of procedural complexity with important ramifications on patient scheduling, endoscopy room staffing, sedation requirements and risk of sedation-related complications $[9,10]$. Thus, there is considerable interest in interventions to effectively reduce cecal intubation time, and consequently, total procedure time. Both patient and endoscopist factors contribute to cecal intubation time and total procedure time, the presence colonic contractility being one such patient-related factor.

We aimed to study the effect of glucagon during colonoscopy on key parameters such as cecal intubation time, total procedure time, patient experience, endoscopist perception of ease of procedure and polyp detection.

\section{Methods}

\section{Study Design and Setting}

We performed a prospective, double-blind, placebo-controlled randomized trial studying the effect of glucagon during colonoscopy. The study was conducted at Zuckerberg San Francisco General Hospital and Trauma Center (ZSFG), an academic, safety net institution (i.e., provides a significant level of care to low income, uninsured and vulnerable populations in the city of San Francisco) affiliated with the University of California, San Francisco (UCSF). Patients are ethnically diverse, and many are immigrants with more than 20 different languages spoken by patients.

\section{Study Eligibility}

Patients presenting to the ZSFG endoscopy unit for colonoscopy by the primary investigator (JPC) between July 2014 to May 2017 were screened for enrollment. Inclusion criteria included patients aged 50-70 years scheduled for outpatient colonoscopy solely for the indication of "positive fecal immunochemical test" (FIT). Exclusion criteria for the study included refusal to provide consent, age younger than 18 or older than 70, prior abdominal surgery, pheochromocytoma, insulinoma, pregnancy, prior colonic neoplasms, prior colonic surgery and end-stage liver disease with Child-Pugh score greater than six. Informed consent was obtained in the patient's primary language. Patient questionnaires printed in English, Chinese, and Spanish were utilized for the study.

\section{Sample Size and Statistical Analysis}

Sample size calculation was performed using cecal intubation time as the primary outcome parameter. Based on a prior randomized study, mean cecal intubation time was noted to be 294 seconds in the glucagon group and 370 seconds in the placebo group with a standard deviation of 140 seconds [8]. Using a power of 0.9 and an alpha of 0.05 , a total sample size of 134 was calculated. Categorical data were compared by the $\chi^{2}$-test or Fisher Exact test where appropriate and numerical data were compared by the Student's t-test. Statistical significance was defined as a two-sided p-value $<0.05$.

\section{Randomization}

Initial randomization was performed with optimism that 200 patients could be enrolled in the study, despite a sample size calculation of 134. Randomization was performed using a sealed envelope technique by the nurse study coordinator and/or the research protocol assistant (vide infra). Two hundred cards with either glucagon or placebo written on them in a 1:1 distribution was used. These cards were shuffled by the study coordinator and placed individually into opaque envelopes. The envelopes themselves were handed to a research assistant and shuffled again. Each envelope was placed in a larger opaque envelope serially labeled from 1-200. Following consent, patients were serially assigned a study number starting with number 1 . Prior to the procedure, but after signed written consent, a non-procedural nurse opened the envelope associated with the patient's study number in seclusion and drew up $1 \mathrm{mg}$ of glucagon in 1 milliliter [ml] of normal saline (NS) or $1 \mathrm{ml}$ of NS alone (the placebo) in accordance with the card within the envelope. Glucagon, a white powder, is reconstituted with $1 \mathrm{ml}$ of NS, making it impossible to identify study drug by the appearance of the syringe to anyone in the procedure room. Thus, all persons in the examination room, including patient, nursing personnel and operator physicians, were blind to patient randomization. Due to scheduling conflicts and factors outside the control of study designers, study enrollment was slower than expected. After two years, Endoscopist 1 enrolled 69 patients. Due to graduation 
of Endoscopist 1, Endoscopist 2 was added to the study and 31 additional patients were enrolled until Endoscopist 2's graduation. Once 100 patients were enrolled, decision was made to conclude the study and perform data analysis. Due to initial randomization with 200 cards, the two endoscopists had unequal distribution of patients receiving glucagon or placebo (Figure 1).

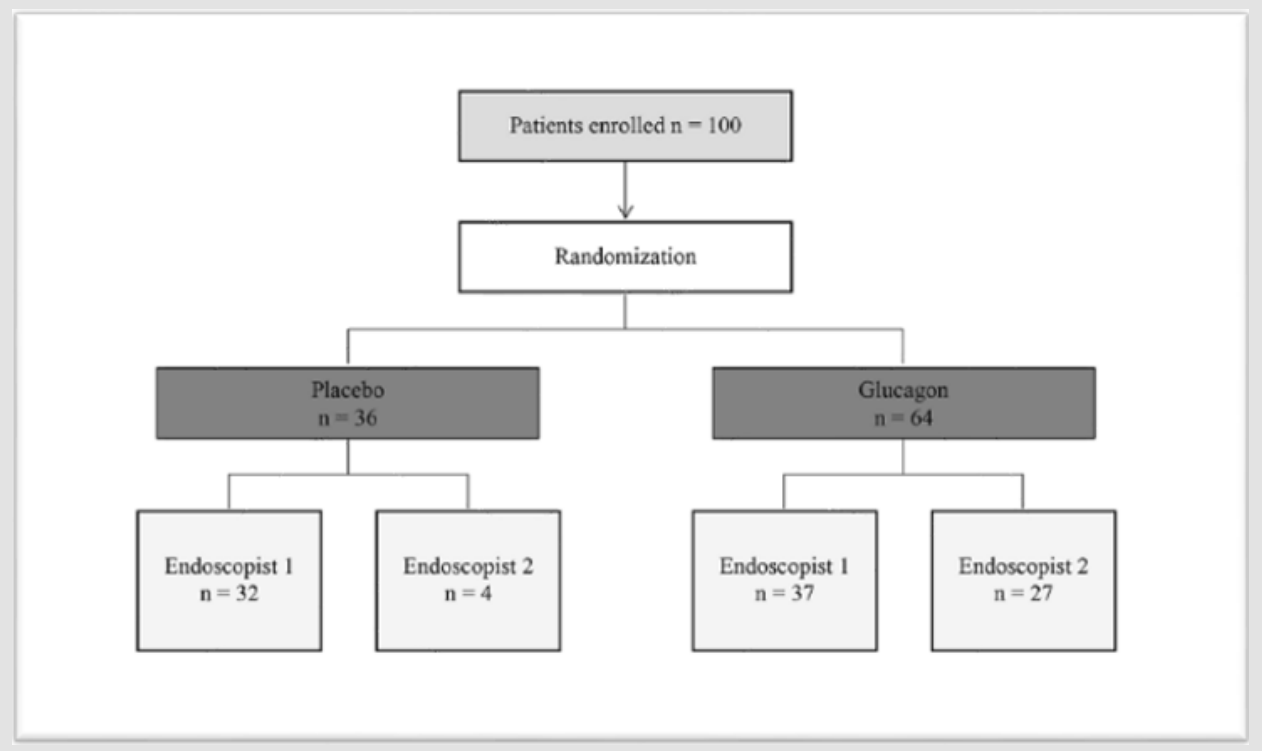

Figure 1: Due to initial randomization with 200 cards, the two endoscopists had unequal distribution of patients receiving glucagon or placebo.

\section{Colonoscopy Procedure}

All patients underwent complete bowel preparation using splitdose US Food and Drug Administration-approved preparations. Procedures between July 2014 to June 2016 was performed by one of two senior gastroenterology fellows, Endoscopist 1 (AA) with primary investigator (JPC) as supervisor. Procedures between October 2016 to May 2017 were performed by a second senior gastroenterology fellow, Endoscopist 2 (TDK) with primary investigator (JPC) supervision. As a result of performing the studies with gastroenterology fellows who were rotating through ZSFG as part of their clinical rotations, non-consecutive patients were enrolled in the study. At the beginning of each procedure, time of scope insertion was recorded by the nurse. The primary investigator, upon visualizing classic triangular folds of the transverse colon, requested the procedural nurse to administer the study drug. Given a glucagon half-life of 8-18 minutes, drug administration for our study was performed once the colonoscope reached the splenic flexure, thus ensuring glucagon activity during both the later part of the insertion phase and the withdrawal phase. Time of medication administration was recorded for all patients. The nursing staff also recorded the following: cecum intubation time, start of colonoscope withdrawal time, total procedure time, and amount of sedatives used for the procedure.

\section{Outcome Measurements}

Key parameters, such as cecal intubation time, total procedure time, ADR, serrated adenoma detection rate (SDR), neoplasia detection rate (NDR), degree of spasm, adequacy of visualization, scope manipulation and patient pain score were prospectively recorded. ADR was defined as the proportion of subjects with at least one traditional adenoma (including tubular or villous adenomas, and adenomas with high grade dysplasia or adenocarcinoma) of any size. SDR was defined as the proportion of subjects with at least one serrated polyp (serrated adenoma or traditional serrated adenoma) and NDR was defined as the percentage of colonoscopies in which at least one traditional adenoma or serrated adenoma was found. Immediately following the procedure, the Endoscopist rated the difficulty in scope manipulation, adequacy of mucosal visualization and the severity of spasms experienced during the colonoscopy on a visual analog scale from 1-10. The following day, patients answered a written questionnaire documenting pain, abdominal fullness, and willingness to accept a future colonoscopy on a visual analog scale from 1-10 and returned the questionnaire to the study coordinator in a pre-stamped, pre-addressed envelope.

\section{Study Oversight}

The study was approved by the Committee of Human Research at UCSF. All enrolled patients provided informed consent. The study was registered a priori on ClinicalTrials.gov (NCT02078726). Data collection was performed for abstract submission and after completion of enrollment in the study. The listed authors had sole responsibility for the study design, data collection, decision to submit the manuscript for publication, and drafting of the manuscript.

\section{Results}

A total of one hundred patients were recruited into the study. Thirty-six patients were randomized into the placebo group and 
64 patients into the glucagon group. No significant difference in patient characteristics were noted between the groups (Table 1). Time to cecum (507 sec vs. $392 \mathrm{sec}$; $=0.0464$ ) and total procedure time (1353 sec vs. $1139 \mathrm{sec}$; $\mathrm{p}=0.0325$ ) were noted to be significantly shorter in the glucagon group when compared to placebo. Withdrawal time was not significantly different between the two groups (760 sec vs. $684 \mathrm{sec}$; $\mathrm{p}=0.2990$ ). Endoscopist perception of scope difficulty was noted to be significantly easier with glucagon (1.40 vs. 2.56; $\mathrm{p}=0.0098$ ), however, no difference in "spasm" score ( 1.90 vs. $1.57 ; \mathrm{p}=0.5018$ ) or mucosal visualization (2.07 vs. 1.26; $p=0.0701$ ) was noted. No significant differences in patient perception of pain ( 1.60 vs. 1.50 ; p=0.8617), abdominal bloating ( 2.38 vs. $2.12 ; \mathrm{p}=0.7381$ ) or willingness to undergo repeat colonoscopy ( 2.10 vs. 1.73 ; $\mathrm{p}=0.6479$ ) were noted. Adenoma per colonoscopy (1.03 vs 1.16; $\mathrm{p}=0.7588$ ) and ADR (33.33\% vs $43.75 \%$; $\mathrm{p}=0.3959$ ) were not statistically different between the two groups. Serrated polyp per colonoscopy ( 0 vs. $0.11 ; \mathrm{p}=0.1125$ ) and SDR ( $0 \%$ vs $7.81 \%$; $p=0.1564$ ) were likewise not statistically significant between the two groups, however, a trend toward higher SDR was seen in the glucagon group. NDR was $33.33 \%$ and $48.44 \%$ respectively for the placebo and glucagon group. Although the NDR was not statistically significant $(\mathrm{p}=0.2065)$, a trend towards improved neoplasia detection rate was seen in the glucagon group.

Table 1.

\begin{tabular}{|c|c|c|c|}
\hline & Placebo & Glucagon & p value \\
\hline $\mathrm{n}$ & 36 & 64 & \\
\hline Age (years) & 59.63 & 60.64 & 0.4861 \\
\hline Sex (female, \%) & $19(52.77)$ & $30(46.88)$ & 0.6777 \\
\hline Ethnicity & & & \\
\hline Asian & 12 & 30 & 0.2112 \\
\hline Hispanic & 9 & 16 & 1 \\
\hline Caucasian & 9 & 14 & 0.8059 \\
\hline African American & 5 & 4 & 0.2767 \\
\hline Other & 1 & 0 & 0.36 \\
\hline BMI & 27.91 & 30.4 & 0.0668 \\
\hline Diabetes & 8 & 18 & 0.6369 \\
\hline Tobacco use & 5 & 21 & 0.0564 \\
\hline
\end{tabular}

\section{Discussion}

Our primary finding was that time to cecum and total procedure time were significantly shorter for patients who received glucagon, which carries important economic implications, especially when paired with the trend noted in this study towards improved NDR with glucagon use. Shorter cecal intubation time and total procedure time was a surprising finding given that study drug was administered when the colonoscope was advanced to the level of the splenic flexure. When time to cecum was subdivided into time to medication administration and time between medication administration and cecal intubation, a statistically significant difference was seen in the time to medication administration between the two groups. The etiology of this difference is unclear.
A possible confounder for the difference in time to cecum between the two groups is notable if procedure times are evaluated for each Endoscopist separately (Table 2). Endoscopist 2 took less time at reaching the cecum than Endoscopist 1. Endoscopist 2 however performed a larger percentage of the glucagon cases than placebo cases (42\% vs $11 \%$ ), thus possibly contributing to faster cecal intubation time in the glucagon group. However, improvement in the perception of Endoscopist scope difficulty scores with glucagon use suggests that an association between glucagon use and faster cecal intubation time exists. Prior studies have reported an association between cecal intubation time and perceived colonoscopy difficulty $[11,12]$ (Tables 3 \& 4). This was again demonstrated in our study as both cecal intubation time and endoscopist assessment of scope difficulty (Table 5) are statistically improved in the glucagon group.

Table 2: Procedure time.

\begin{tabular}{|c|c|c|c|}
\hline & Placebo & Glucagon & P value \\
\hline Time to cecum (sec) & 507.86 & 392.42 & 0.0464 \\
\hline Time to med administration & 264.39 & 189.55 & 0.0099 \\
\hline Med admin to cecum (sec) & 243.47 & 203.55 & 0.341 \\
\hline Withdrawal Time (sec) & 760.28 & 683.98 & 0.299 \\
\hline Total procedure time (sec) & 1353.58 & 1139.17 & 0.0325 \\
\hline
\end{tabular}

Note: $\mathrm{Sec}=$ second

\begin{tabular}{|c|c|c|c|}
\hline & Placebo N=32 & $\begin{array}{c}\text { Glucagon } \\
\text { N=32 }\end{array}$ & P value \\
\hline Time to cecum (sec) & 522.38 & 403.27 & 0.1059 \\
\hline $\begin{array}{c}\text { Time to med } \\
\text { administration }\end{array}$ & 276.03 & 204.59 & 0.061 \\
\hline Med admin to cecum (sec) & 246.34 & 198.68 & 0.361 \\
\hline Withdrawal Time (sec) & 782.53 & 690.46 & 0.3271 \\
\hline Total procedure time (sec) & 1398.91 & 1160.62 & 0.0534 \\
\hline
\end{tabular}

Note: Procedure time by Endoscopist 1.

\begin{tabular}{|c|c|c|c|}
\hline & Placebo N=4 & Glucagon N=27 & P value \\
\hline Time to cecum (sec) & 391.75 & 377.56 & 0.8995 \\
\hline $\begin{array}{c}\text { Time to med } \\
\text { administration }\end{array}$ & 171.25 & 168.93 & 0.9525 \\
\hline Med admin to cecum (sec) & 220.5 & 210.22 & 0.9109 \\
\hline Withdrawal Time (sec) & 582.25 & 675.11 & 0.5048 \\
\hline Total procedure time (sec) & 991 & 1109.78 & 0.5802 \\
\hline
\end{tabular}

Note: Procedure time by Endoscopist 2

Table 3: Detection Rates.

\begin{tabular}{|c|c|c|c|}
\hline & Placebo & Glucagon & P value \\
\hline Adenoma per colonoscopy (APC) & 1.03 & 1.16 & 0.7588 \\
\hline Adenoma detection rate (ADR) & $33.33 \%$ & $43.75 \%$ & 0.3959 \\
\hline Serrated polyp per colonoscopy (SPC) & 0 & 0.11 & 0.1125 \\
\hline Serrated polyp detection rate (SPR) & 0 & $7.81 \%$ & 0.1564 \\
\hline $\begin{array}{c}\text { Neoplasia detection per colonoscopy } \\
\text { (NPC) }\end{array}$ & 1 & 1.27 & 0.5244 \\
\hline Neoplasia detection rate (NDR) & $33.33 \%$ & $48.44 \%$ & 0.2065 \\
\hline
\end{tabular}


Table 4: Patient questionnaire responses.

\begin{tabular}{|c|c|c|c|}
\hline & Placebo & Glucagon & P value \\
\hline Pain & 1.603 & 1.497 & 0.8617 \\
\hline Bloating & 2.376 & 2.12 & 0.7381 \\
\hline Willingness to repeat Colonoscopy & 2.1 & 1.73 & 0.6479 \\
\hline
\end{tabular}

Table 5: Endoscopist Questionnaire results.

\begin{tabular}{|c|c|c|c|}
\hline & Placebo & Glucagon & P value \\
\hline Spasm score & 1.909 & 1.566 & 0.5018 \\
\hline Scope Difficulty & 2.563 & 1.402 & 0.0098 \\
\hline Visualization & 2.069 & 1.256 & 0.0701 \\
\hline
\end{tabular}

Detailed analysis of adenoma and serrated adenoma detection with glucagon use has not been performed before. This study was not powered to examine outcomes like adenoma and neoplasia detection rates, however, a trend towards improved detection, specifically, serrated polyp detection was seen with glucagon use and warrants further evaluation in larger studies. This prospective, randomized, placebo study was double-blinded, minimizing the chance for bias. Additionally, all colonoscopies were supervised by a single, expert endoscopist with experience of over 10,000 colonoscopies which mitigated any potential for confounding factors had multiple endoscopists been utilized. Furthermore, detailed analysis of adenoma and serrated adenoma detection has never been performed before and this study identified a signal/ trend towards improved detection in the glucagon group that warrants further investigation in a larger study powered to examine this outcome.

The results should be interpreted with recognition of the limitations of this study. First, calculated sample size to answer the primary endpoint of cecal intubation was not reached. The major implication of this is that the study may have been underpowered to identify differences. Furthermore, the study was not powered to examine other potentially clinically meaningful outcomes such as adenoma and neoplasia detection rates. Second, patients received sedation for their procedures, which had the potential to impact their response to questionnaires despite being specifically instructed to fill out their answers at least one day following the procedure to mitigate amnestic sedative effects. However, there is no reason to believe this would affect the placebo or glucagon differently and patients received similar amounts of sedative medications in both groups. Lastly, while a single endoscopist supervising all procedures prioritized internal validity of the study, this may limit the potential recruitment of patients and generalizability of the results to other endoscopists. Thus, future larger studies powered to examine the outcome of neoplasia detection rate could consider utilizing multiple endoscopists.

\section{Conflict of Interest/ Study Support}

Guarantor of the article: Anupam Aditi, John P Cello, Specific author contributions.

\section{References}

1. Winawer SJ, Zauber AG, Ho MN, Ho MN, O’Brien MJ, et al. (1993) Prevention of colorectal cancer by colonoscopic polypectomy. NEJM 329(27): 1977-1981.

2. (2010) Centers for Disease Control and Prevention (CDC) Behavioral Risk Factor Surveillance System Survey Data Atlanta, Georgia US Department of Health and Human Services, Centers for Disease Control and Prevention.

3. Sanagapalli S, Agnihotri K, Rupert Leong, Crispin John Corte (2017) Antispasmodic drugs in colonoscopy: a review of their pharmacology, safety and efficacy in improving polyp detection and related outcomes. Therap Adv Gastroeterol 10(1): 101-113.

4. Chowdhury AR, Lorber SH (1977) Effect of glucagon and secretin on food or morphine induced motor activity of the distal colon, rectum and anal sphincter. Am J Dig Dis 22(9): 775-780.

5. Taylor I, Duthie HL, Cumberland DC, Smallwood R (1975) Glucagon and the colon Gut 16(12): 973-978.

6. Jamal MM, Palmer RC, Harrington DM (1992) Glucagon facilitates colonoscopy-a double blind study [abstract]. American Journal of Gastroenterology 87: 1323.

7. Cutler CS, Rex DK, Hawes RH, Glen A Lehman (1995) Does routine intravenous glucagon administration facilitate colonoscopy? Gastrointestinal Endoscopy 42(4): 346-350.

8. Tamai N, Matsuda K, Sumiyama K, Yoshida Y, Tajiri H (2013) Glucagon facilitates colonoscopy and reduces patient discomfort: a randomized double-blind controlled trial with salivary amylase stress analysis. European Journal of Gastroenterology and Hepatology 25(5): 575-579.

9. Bernstein C, Thorn M, Monsees K, Rhonda Spell, J Barry O'Connor (2005) A prospective study of factors that determine cecal intubation time at colonoscopy. Gastrointestinal Endoscopy 61(1): 72-75.

10. Al Moussawi $\mathrm{H}, \mathrm{Al}$ Khatib $\mathrm{M}, \mathrm{El}$ Ahmar M, Al Masri H, Leddy A, et al (2017) The effect of premedication with peppermint oil capsules prior to colonoscopy A double blind randomized placebo-controlled trial 18(4): 220-223.

11. Saunders B, Williams C (1996) Premedication with intravenous antispasmotics speeds colonoscope insertion. Gastrointest Endosc 43(3): 209-211.

12. Corte C, Kim A, Kaffes A (2010) Objective measures of colonoscopic difficulty: correlation with polyp detection and operator perception. Gastrointest Endosc 71(5): AB215-AB216. 
ISSN: 2574-1241

DOI: 10.26717/BJSTR.2019.22.003713

Alex Rodas. Biomed J Sci \& Tech Res

(C) (1) This work is licensed under Creative

Submission Link: https://biomedres.us/submit-manuscript.php

\begin{tabular}{ll} 
BIOMEDICAL & \multicolumn{1}{c}{ Assets of Publishing with us } \\
RESEARCHES & - Global archiving of articles \\
- Immediate, unrestricted online access \\
- Rigorous Peer Review Process \\
https://biomedres.us/
\end{tabular}

